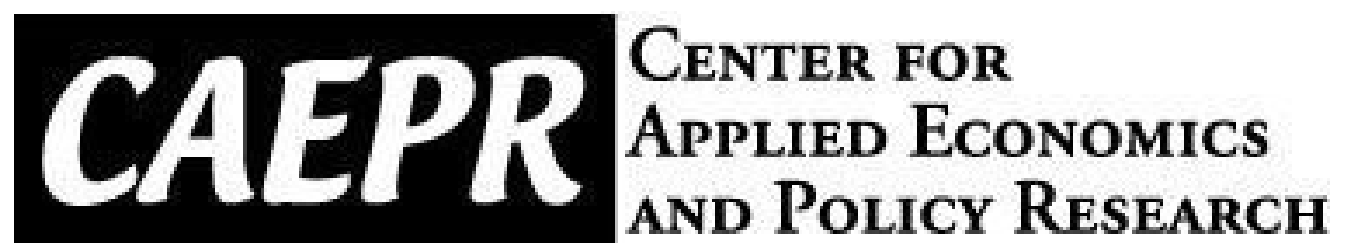

\author{
CAEPR \\ Working Paper \\ \#2018-005
}

Domestic Spillovers and Foreign Networks in Exporting

\author{
Shibi He \\ Indiana University \\ Volodymyr Lugovskyy \\ Indiana University
}

July 1, 2018

This paper can be downloaded without charge from the Social Science Research

Network electronic library at https://papers.ssrn.com/abstract id=3207733

The Center for Applied Economics and Policy Research resides in the Department of Economics at Indiana University Bloomington. CAEPR can be found on the Internet at: http://www.indiana.edu/ caepr. CAEPR can be reached via email at caepr@indiana.edu or via phone at 812-855-4050.

(C)2018 by Shibi He and Volodymyr Lugouskyy. All rights reserved. Short sections of text, not to exceed two paragraphs, may be quoted without explicit permission provided that full credit, including (C) notice, is given to the source. 


\title{
Domestic Spillovers and Foreign Networks in Exporting
}

\author{
Shibi He* \\ Volodymyr Lugovskyy ${ }^{\dagger}$
}

July 1, 2018

\begin{abstract}
We explore the effects of Domestic Spillovers (other domestic firms exporting a good to a given country) and Foreign Networks (links to other countries via firm's trading partners) on the firm's choice of new export destinations. By matching Colombian exporting and Chilean importing and exporting firms between 2007 and 2016, we show that both effects matter and that they amplify each other. Jointly these effects are more important than geographic proximity measures, import and export growth, and market size combined. Domestic spillovers are relatively more important, especially for identifying the persistent exporters, which export to a new destination for more than a year.
\end{abstract}

Keywords: Firm-level, Spillover, Networks, Trade.

JEL Classification Number: F1, L14

*Department of Economics, Indiana University, Wylie Hall, 100 S. Woodlawn, Bloomington, IN 47405-7104; e-mail: shibhe@indiana.edu

${ }^{\dagger}$ Department of Economics, Indiana University, Wylie Hall Rm 301, 100 S. Woodlawn, Bloomington, IN 47405-7104; e-mail: vlugovsk@indiana.edu 


\section{Introduction}

Expansion to new foreign markets - an important factor for export diversification and economic growth ${ }^{1}$-is subject to sizable information uncertainty and risk. Firms are known to employ the following three strategies to alleviate this type of risk. First, they utilize the information from exports of other domestic firms-Domestic Spillover effect (Greenaway et al. (2004), Silvente and Giménez (2007), Koenig et al. (2010)). Second, they leverage their own experiences by employing so-called 'sequential exporting' strategy (Eaton et al. (2009) Albornoz et al. (2012), Nguyen (2012)). Third, they search through their trading partners who may facilitate securing new trading partners - Foreign Export Network effect (Chaney (2014), He (2018)).

We provide three major contribution to the existing literature on this topic. We are the first to assess the joint effects of domestic spillovers and foreign networks while keeping the sequential exporting effect constant. Previous research studied these effects in isolation. We also use a finer, firm-to-firm measure of networks, which is more accurate and informative than the previously used firm-to-country measure of networks. Finally, we explore whether, in addition to previously explored foreign exporting networks, foreign importing networks and domestic importing networks also have an effect on the firm's choice of new export destinations.

Our empirical approach can be described as follows. Using the transaction-level data of Colombian exports between 2007 and 2016, we first identify 183 Colombian exporting firms which originally export only to Chile and later expand to a new destination. Using Chilean firm names recorded in the Colombian Exports and Chilean Imports transaction data between 2007 and 2016 we try to match these 183 Colombian firms to their Chilean importing counterparts. We successfully match 163 Colombian firms and drop the remaining 20 unmatched firms. These matches, along with the additional transaction dataset on Chilean Exports allow us to construct two network dummy variables. The Chilean Exports Network dummy is equal to one for all destinations to which a matched Chilean firm exports and zero for all other destinations. Similarly, the Chilean Imports Network dummy is equal to one for all destinations from which the matched Chilean firm imports and zero otherwise. Next, we match Colombian exports and imports data (using additional Colombian transaction-level Imports data)

\footnotetext{
${ }^{1}$ Hausmann and Rodrik (2003)
} 
and construct the Colombian Imports Network dummy for each of the 163 firms by setting it to one for all destinations from which the firm imports and to zero otherwise.

In addition, for each of the matched 163 Colombian firms, we construct a Spillover dummy, equal to one for all destinations for which a product of the expanding firm was exported by at least one other Colombian firm in the previous year and to zero otherwise. We also complement the constructed set of dummies with the standard control variables used by Chaney (2014), such as geographic proximity measures, import and export growth rates, and market size.

Using the constructed dataset, we employ a dynamic Probit model ${ }^{2}$ to explore which factors affect the choice of the new exporting destinations by Colombian exporting firm in year $t+1$ given that in year $t$ it exports only to Chile. This approach allows us to control for the sequential exporting effect-by construction, it is exactly the same for all firms in our sample - and to jointly estimate Domestic Spillover (DS), Foreign Export Network (FEN), Domestic Import Network, and Foreign Import Network effects at the firm-to-firm level.

We find that, out of these four, only DS and FEN have statistically significant effects on the expansion path. Jointly, DS and FEN have a more important effect than all other factors (including proximity, import and export growth rates, and market size) combined. While DS has a relatively stronger marginal effect, both DS and FEN have economically significant effects which amplify each other. For example, the probability of choosing the U.S. as the next export destination is only $2.7 \%$ if neither of the effects DS and FEN effects is present, 7.8\% with the FEN effect only, 15.9\% with the DS effect only, and $31.2 \%$ if both FEN and DS effects are present. ${ }^{3}$

We also find that omitting the Domestic Spillover dummy from the empirical specification significantly increases the magnitudes of almost all other coefficients in the Probit specification, ${ }^{4}$ which suggests a pronounced omitted variables bias. Omitting the all three Network dummies, on the other hand, has only a marginal effect on all

\footnotetext{
${ }^{2}$ As we show in Appendix, the results are very similar to those obtained with the dynamic Logit model.

${ }^{3}$ The corresponding numbers are $0.3 \%, 1.1 \%, 3.1 \%, 8.6 \%$ for Mexico, $0.3 \%, 1.4 \%, 3.7 \%, 10.1 \%$ for Honduras, $0.05 \%, 0.3 \%, 0.9 \%, 3.2 \%$ for Ukraine, and $0.1 \%, 0.4 \%, 1.2 \%, 4 \%$ for Zimbabwe.

${ }^{4}$ Namely, the FEN coefficient increases by 1.5 times, many other coefficients increase by 2-3 times.
} 
other coefficients. Thus, the omitted variables bias seems to be a strong concern for omitting the Spillover dummy but not for omitting the Network dummies.

Most of the Colombian new exports have been shown short lived: Eaton et al. (2007) show that two thirds of them do not survive to the second year. That is why, we also examine which factors contribute to persistent export expansion. To this goal, we introduce a new dependent variable, the Survival dummy, defined as one if exports to a new destination continue for more than a year and zero otherwise. ${ }^{5}$ By using the same set of dependent variables, we find that only the DS has a statistically significant effect on the Survival. That is, for firms with minimal export networks and only one prior country of exporting, domestic spillovers is the single and most important factor of the persistent exporting to new destinations. This result re-emphasizes the importance of spillovers generated by export pioneers for other firms (Hausmann and Rodrik, 2003) and the fact that pioneers face high risks of failure (Wagner and Zahler, 2015).

We recognize that our results are at best representative only for exporting firms from developing countries which initially export to only one other (developing) country. At the same time, the constraints imposed on our sample by the data availability have certain advantages when examining networks effects. We are focusing on the exporters with a minimal FEN-typically consisting of just one Chilean firm. As demonstrated both theoretically and empirically by Chaney (2014), the expansion is the least likely to happen for such firms since their networks are minimalistic. Thus, showing that the FEN have both statistically and economically significant effects on expansion path even for the smallest possible networks provides even stronger support for network theory in this context.

Furthermore focusing on firms with a single trade partner allows to downplay additional, more complex effects present in larger networks, such as reputation effects, homophile $^{6}$, segregation, etc. ${ }^{7}$ For example, a firm with multiple trading partners potentially is likely to have a stronger reputation in the eyes of the potential new partners

\footnotetext{
${ }^{5}$ Similarly to previous studies on export spells of Colombian firms, only one third of new export expansions results in the persistent exporting.

${ }^{6}$ The widely known analog of homophily effect in trade is Linder effect-firms are more likely to export to countries with the similar income per capita as the one in their own country.

${ }^{7}$ See, for example, Currarini et al. (2009) and Jackson and Zenou (2015) for a more detailed description of these and other additional effects in larger social netwroks.
} 
since it projects higher quality and reliability than a firm with only few partners. Thus, even if a new partner is met without direct involvement of the existing partner, being a part of the larger network might have facilitated the match. Focusing on the firms with a minimal network allows to isolate these effects.

The rest of the paper is organized as follows. Section 2 discusses related literature.

Section 3 provides a detailed data description. Section 4 presents empirical models and the estimation results. Section 5 concludes.

\section{Related Literature}

This paper contributes to several strands of literature. Most directly, it adds to a large literature on firms' expansion in the international markets. The existing literature has identified three strategies that firms utilize to expand into new markets: domestic information spillover, foreign networks, and sequential exporting.

The literature on the domestic spillovers is probably the largest one among the three. It emphasizes the pool of existing exporters as an important source of information for other firms (Koenig et al., 2010). Firms tend to learn about the profits, requirements, and challenges in the overseas markets by observing other firms' exporting experience, and they tend to imitate the export behavior of the more successful, more experienced leaders. Clerides et al. (1998), Silvente and Giménez (2007), Koenig (2009), and Koenig et al. (2010) used firm-level data from different countries to show that a firm's decision to start exporting and/or the volume exported by the firm are positively affected by their neighboring firms. Aitken et al. (1997), Greenaway et al. (2004), and Kneller and Pisu (2007) identified the multinationals as one of the most important sources of information spillover. Iacovone and Javorcik (2010) used Mexican export data to show that once a firm starts exporting a new product, other firms will soon export the same products. Wagner and Zahler (2015) explore detailed data on new exporters in Chile and find that followers are $40 \%$ more likely to enter a product if a pioneer survives more than one year exporting.

Our contribution to this literature is twofold. First, when examining the spillover effects, we control for other important effects, including network and sequential-export 
effects. Second, we can rank the magnitude of the spillover effect versus other effects. We find that for the firms with small exporting networks, the spillover effects is much more important. Specifically, it has the highest economic significance for the expansion path, and it is the only statistically significant factor affecting the survival of exports to a new destinations for more than a year. Importantly, omitting the spillover effect in the empirical specification leads to very pronounced upward biases of other effect.

The literature on networks and trade dates back to Rauch (1999) who introduced the idea that informational frictions dampen trade and thus the social networks between buyers and sellers help reducing these frictions and promote trade. ${ }^{8}$ While a more recent strand of the literature empirically estimates the trade-creating effect of networks using country-specific case studies, ${ }^{9}$ it is relatively silent on the expansion path at the firm level.

Do exporting firms rely on their networks of existing trade partners to search for new trade partners? This question has been first positively answered by Chaney (2014) who provided the reduced-form evidence of the effect of firm-to-country networks on the export expansion path of French firms ${ }^{10}$ and formally modeled the remote search for new partners through existing trading partners. Building on Chaney (2014)'s work, we provide an additional test of the effect of networks on trade expansion by using a finer firm-to-firm measure of networks of Colombian and Chilean firms. We show that firm-to-firm networks do have a positive effect on the choice of new export destinations even after controlling for the spillover and sequential-exporting effects. Quantitatively, we show that a Colombian firm is $0.42 \%$ more likely to choose a new export destination if its Chilean trade partners exported to that country in the previous period.

Our paper is also related to a new but flourishing literature that focus on the firmto-firm connections in international trade. The vast majority of world trade flows is between firms. However, many empirical studies are restricted to the aggregated trade

\footnotetext{
${ }^{8}$ See also Rauch (2001) and Bernard and Moxnes (2018) for excellent surveys on networks and trade.

${ }^{9}$ Rauch and Trindade (2002), Combes et al. (2005), Greaney (2009), Garmendia et al. (2012), and Aleksynska and Peri (2014) while using different methodologies and/or datasets, arrive at the same conclusion that the cultural, social, and business networks can largely facilitate international trade.

${ }^{10}$ Specifically he showed that firms are more likely to choose a new export destination that is closely related to the network they belong to.
} 
due to the scarcity of the detailed trade transaction data between firms. Recently, with the increasing availability of firm-to-firm trade data, the literature has started to explore the role of the connections between individual exporters and importers. For example, Rauch and Watson (2004), Antras and Costinot (2011), Petropoulou (2008), and Chaney (2014) model intermediaries as agents that facilitate matching between exporters and foreign buyers. Benguria (2015) proposes a model to analyze the sorting and matching between exporting and importing firms and provides empirical evidence in support of this theory. Other papers examine the cross-section of trading relationships between exporters and importers (Eaton et al. (2009), Blum et al. (2010), Blum et al. (2012), Monarch (2014), Bernard et al. (2014), and Dragusanu (2014)). We show that these connections are critical for a firm's choice of new export destinations.

\section{Data Description}

Our primary data source is the customs records of Colombian and Chilean import and export transactions between 2007 and 2016. ${ }^{11}$ A transaction record includes the firm's national tax ID number, the product code at Harmonized System (HS) 10-digit level, ${ }^{12}$ the value of the transaction in US dollars, the country of destination for export data, and the country of origin for import data. Importantly, in the Colombian exports data, we also observe the names of foreign importing firms, which allows us to identify Chilean firms which import from Colombia. ${ }^{13}$

Dependent Variables: Entry and Survival. Using Colombian transaction-level export data, we first identify 183 Colombian exporters which originally export only to Chile and later expand to new destinations. Using Chilean firm names recorded in the Colombian Exports and Chilean Imports transaction data, we successfully match 163 of these Colombian firms to their Chilean importing counterparts between 2007 and

\footnotetext{
${ }^{11}$ The data is obtained from Datamyne, a company that specializes in documenting import and export transactions in Americas. For more detail please see www.datamyne.com.

${ }^{12}$ In our paper we need the product dimension only for the Colombian part of the data, which is at HS10.

${ }^{13}$ The names of these Chilean firms are not standardized in the Colombian exports data. There are instances in which the name of the same firm and its address are recorded differently (e.g., using abbreviations, capital and lower-case letters, dashes, etc.). We deal with this problem by standardizing the spelling and the length of the names and by comparing these names to the standardized names of firms in the Chilean imports data. The detailed description of cleaning the exporters' names is provided in the Technical Appendix.
} 
2016. ${ }^{14}$ For these 163 Colombian firms, we define the Entry dummy, Entry $y_{i, c, t+1}$, to be equal to one if, conditional on exporting only to Chile in year $t$ and to a new destination in year $t+1$, it exports to country $c$ and zero if it does not export to country $c$. If $E_{\text {Entr }}{ }_{i, c, t+1}$, is equal to one, and firm $i$ export to country $c$ for longer than one calendar year, we define the Survival dummy, Survival ${ }_{i, c, t+1}$, to be equal to one. Survival Su,,$t+1_{1}$ is equal to zero if new exporting is not shipped to country $c$, or if exporting to $c$ lasts for less than one calendar year.

We consider 182 countries as potential new export destinations for matched Colombian firms, which gives us a total number of 29,666 (=(163 firms) x (182 countries)) possible firm-destination combinations. As shown in the first column of Table 1, we find that Entry dummy is equal to one for 224 of these combinations whereas Survival dummy is equal to one only for 59 of them.That is, conditional on expanding, a firm which previously exported only to Chile will export, on average, to $224 / 163=1.4$ new destinations, but only $26 \%\left(=59 / 224^{*} 100 \%\right)$ of these expansions will survive for more than one calendar year.

Export and Import Network Dummies. The matches between Colombian exporting and Chilean importing firms along with the additional transaction dataset on Chilean Exports allowed us to construct two network dummy variables. The Chilean Export Network dummy, ExpNetwork $k_{i, c, t}$, is equal to one for all firm $c$ 's destinations to which any of its matched Chilean importing firms export and zero otherwise. We observed that only 73 of these matched Chilean firms export (on average to 4.9 destinations), which, as shown in column 4 of Table 1, gives us 358 ones and 29,666-358=29308 zeros for the Export Network dummy variable.

Similarly, the Chilean Import Network dummy, CHL_ImpNetwork $k_{i, c, t}$, is equal to one for all destinations from which the matched Chilean firm imports and zero otherwise. As shown in column 5 of Table 1, we observe 992 ones and 28674 zeros for CHL_ImpNetwork $k_{i, c, t}$.

In addition, we match Colombian exports and imports data and construct the Colombian Import Network dummy variable, COL_ImpNetwor $k_{i, c, t}$, for each of the 163

\footnotetext{
${ }^{14}$ We drop the unmatched 20 Colombian exporting firms from our analysis.
} 
Colombian firms by setting it to one for each country $c$ from which firm $i$ imports and to zero otherwise. We observed 567 ones and 29099 zeros for the Colombian Import Network dummy variable (see column 6 of Table 1).

Domestic Spillover Dummy. For each of the matched 163 Colombian firms, we construct a Spillover dummy variable Spillover $_{i, c, t}$. For each expanding firm, we first identify which HS 10-digit product was exported to the new export destination. We then explore the Colombian transaction-level export data to see if there was any other Colombian firm exporting the same product to the same destination in the previous year. If yes, the the Spillover dummy for that firm-destination pair, Spillover ${ }_{i, c, t}$, is set to one. If not, it is set to zero. As shown in column 3 of Table 1, we observe 4,516 ones and 25140 zeros for the Spillover dummy variable.

Other Variables. Following Chaney (2014), we also use six additional variables to control for geographic proximity, import sources, market size, and export and import growth.

(i) $C H L_{-} \operatorname{Exp} G r o w t h_{i, c, t}$ measures the export growth to country $c$ between years $t$ and $t+1$ of Chilean firms importing from the Colombian firm $i$ :

$$
C H L \_E x p G r o w t h_{i, c, t} \equiv \sum_{j \in K} \frac{\text { Export }_{j, c, t+1}-\text { Export }_{j, c, t}}{\text { Export }_{j, c, t}}
$$

where $K$ is the set of Chilean firms importing from the Colombian firm $i$.

(ii) Overall_ImpGrowt $h_{c, t}$ measures country $c^{\prime}$ s import growth from all other countries between years $t$ and $t+1$ :

$$
\text { Overall_ImpGrowth } h_{c, t} \equiv \sum_{c^{\prime}} \frac{\text { Import }_{c, c^{\prime}, t+1}-\text { Import }_{c, c^{\prime}, t}}{\text { Import }_{c, c^{\prime}, t}}
$$

The bilateral trade data was obtained from the United Nations Comtrade Database. (iii)-(v) Using the bilateral distance data, we compute the proximities between Colombia and other countries:

$$
\text { COL_proximity } \equiv \frac{1}{\text { Dist }_{C O L, c}}
$$


between Chile and other countries:

$$
\text { CHL_proximity }=\frac{1}{\text { Dist }_{C H L, c}} \text {; }
$$

and the average proximity of each country from the rest of the world:

$$
\text { Overall_proximity }{ }_{c} \equiv \frac{1}{N} \sum_{c^{\prime}} \frac{1}{\text { Dist }_{c^{\prime}, c}}
$$

where $N=182$ is the total number of countries in our sample. The data on bilateral distances $\left(\right.$ Dist $_{C O L, c}$, Dist $_{C H L, c}$, Dist $_{c^{\prime}, c}$ ) $)$ is obtained from CEPII. It is calculated as the population-weighted average of the distances between the main cities of two countries.

(vi) The country size of country $c$ in year $t, G D P_{c, t}$, is measured by its nominal GDP (in billions of US dollars), obtained from the Penn World Tables.

Table 1 presents the summary statistics for each variable we use in the empirical specifications and Table 2 lists the correlation coefficients between these variables. Table 2 shows that the correlations between any two independent variables are rather low: the highest correlation coefficients are around $0.3-0.44$, most of them are less than 0.1 . The correlations between the dependent and independent variables are also rather low: the highest ones for both Entry and Survival are with the Spillover dummy: 0.17 and 0.11 respectively.

Graphically, Figure 1 shows the geographic maps for the new destinations that the Colombian firms expand to as well as the export destinations of their peer firms and their matched Chilean trade partners. The intensity of the color represents the frequencies of exports. We can see that there is an overlap between the Colombian firm's new export destinations and the export destinations of their peer firms and Chilean trade partners, suggesting that exporting firms may rely on both domestic spillovers and foreign networks when choosing a new export destination. 

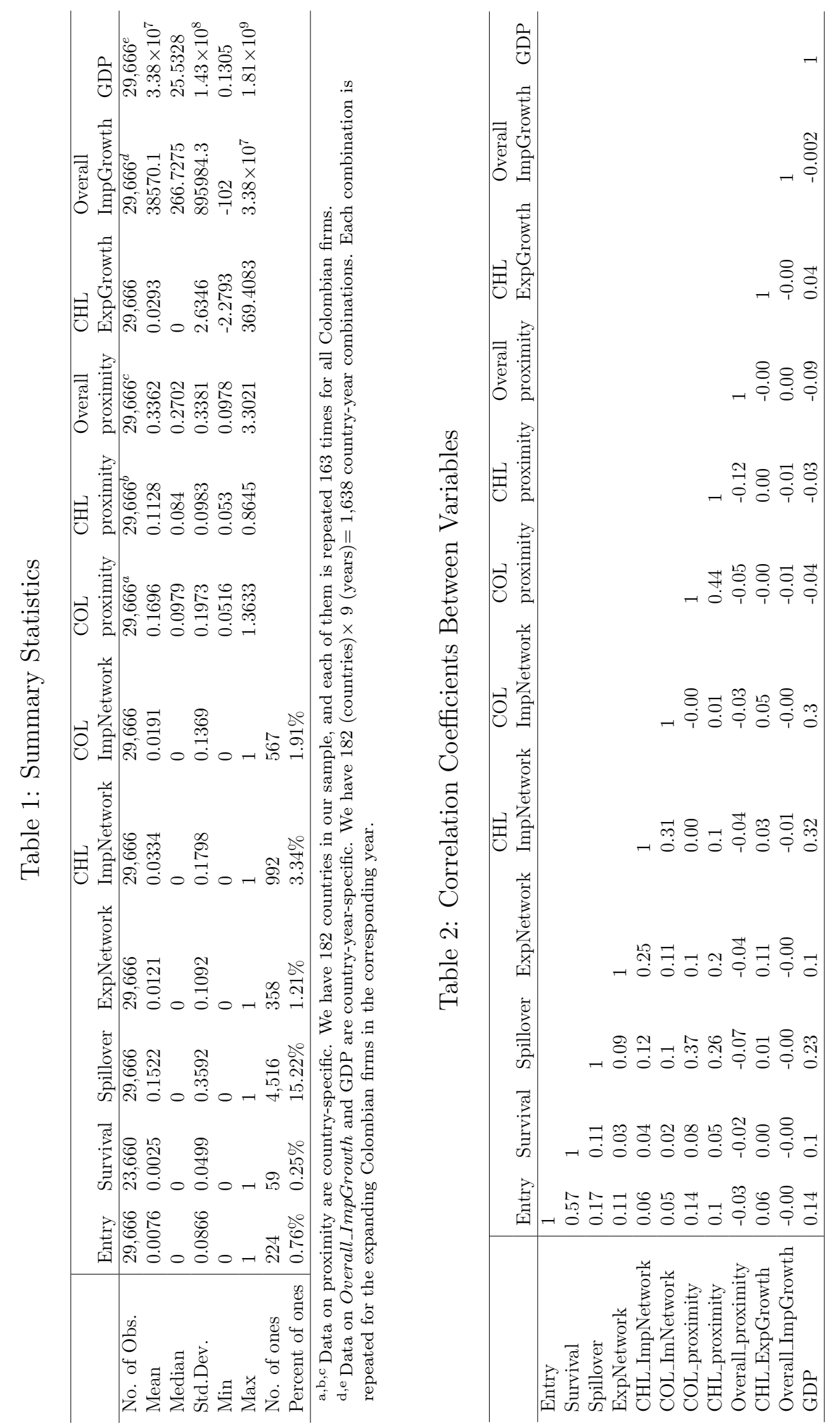


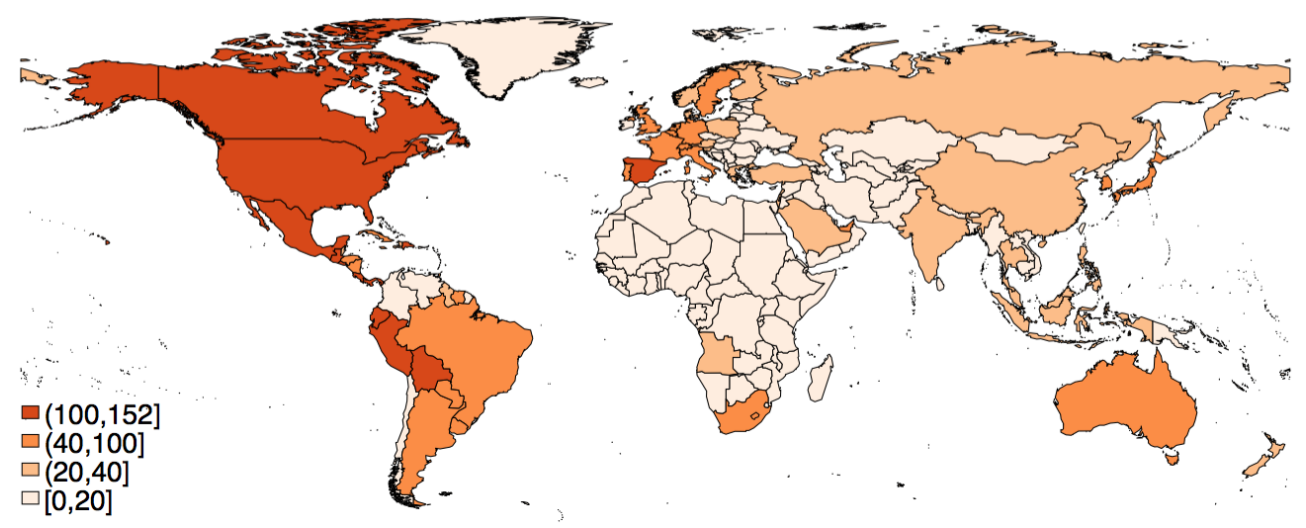

(a) Export destinations of Colombian peer firms

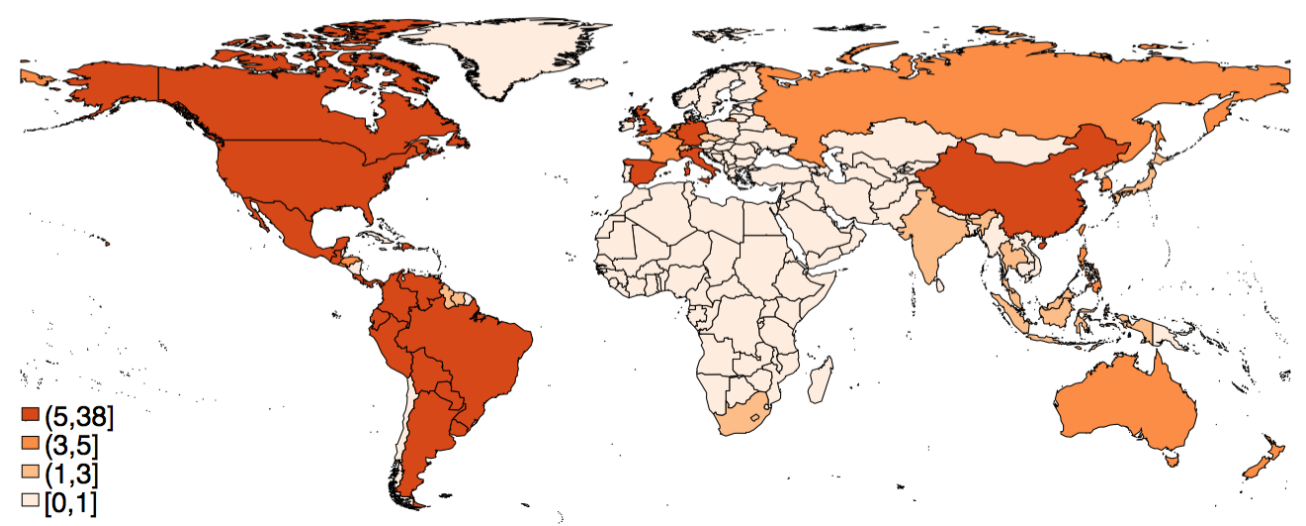

(b) Export destinations of matched Chilean importing firms

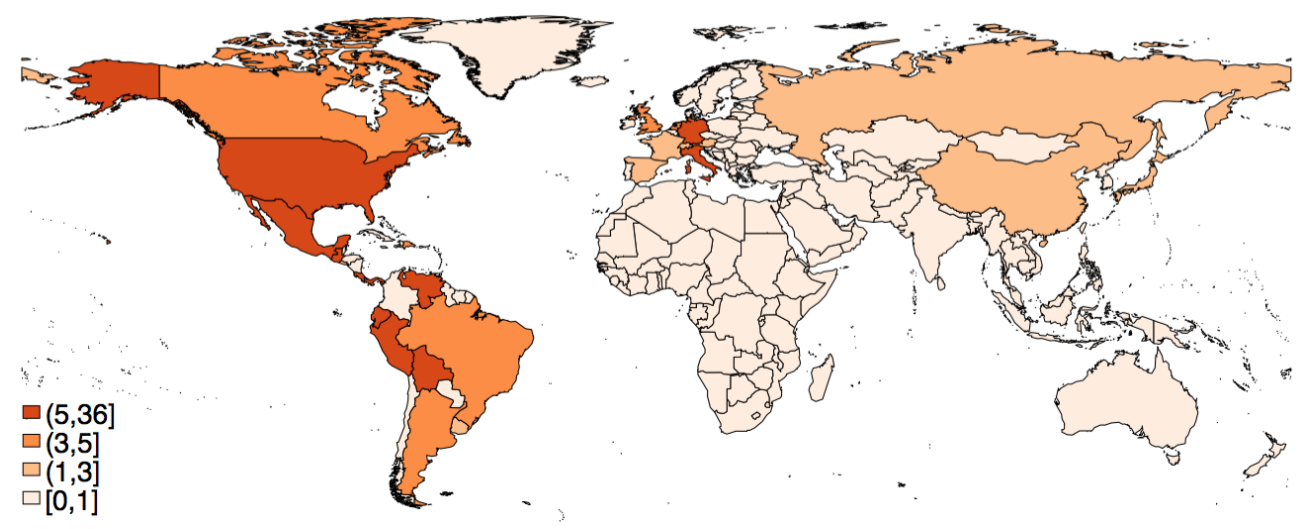

(c) New destinations that Colombian firms expand to

Figure 1: Export Maps of Colombian and Chilean Firms 


\section{Empirical Model and Estimation Results}

In this section, we present the empirical model and explore to which extent firms rely on domestic spillovers and foreign networks when choosing a new export destination. Specifically, we use a dynamic Probit model to examine whether, conditional on expanding its exports to a new destination, a Colombian firm $i$ is more likely to chose country $c$ rather than any other country due to network and domestic spillover effects.

Empirical Model. Building on and expending the empirical model of Chaney (2014), we employ the following specification:

$$
\begin{aligned}
& \text { (1) } \operatorname{Prob}\left(\text { Entry }_{i, c, t+1}>0 \mid \text { observables }\right) \\
& =\Phi\left(\alpha \text { Spillover }_{i, c, t}\right. \\
& +\beta_{1} \operatorname{ExpNetwork}_{i, c, t}+\beta_{2} C H L_{\_} \text {ImpNetwork } k_{i, c, t}+\beta_{3} C O L_{-} \text {ImpNetwor } k_{i, c, t} \\
& +\gamma_{1} \text { COL_proximity }+\gamma_{2} \text { CHL_proximity }+\gamma_{3} \text { Overall_proximity }_{c} \\
& +\lambda_{1} C H L \_E x p G r o w t h_{i, c, t}+\lambda_{2} \text { Overall_ImpGrowt }_{c, t} \\
& \left.+\delta G D P_{c, t}\right)
\end{aligned}
$$

where

$\mathbf{1}\left[\right.$ Entry $\left._{i, c, t+1}>0\right]$ is the dependent variable set to 1 if, conditional on entering a new (other than Chile) country in year $t+1$, firm $i$ enters country $c$ and 0 if not;

$\alpha$ captures the domestic spillover effect among the Colombian firms within the same HS 10-digit product $(\alpha>0$ would indicate that a firm is more likely to chose country $c$ for its expansion if its peers exported the same product to $c$ in the previous year);

$\beta_{1}, \beta_{2}$, and $\beta_{3}$ capture the Foreign Export Network, Foreign Import Network, and Domestic Import Network effects, respectively (e.g., $\beta_{1}>0$ would suggest that firm $i$ has a higher chance to expand to $c$ if its Chilean trading partner exported to $c$ in the previous year) $;^{15}$

$\gamma_{1}, \gamma_{2}$, and $\gamma_{3}$ capture the effects of proximity to Colombia, proximity to Chile, and overall proximity of country $c$, respectively (e.g., $\gamma_{1}$ would indicate that the probability of choosing $c$ as the new market increases in its proximity to Colombia);

\footnotetext{
${ }^{15}$ Similarly, $\beta_{2}$ measures the effects of Chilean import network and $\beta_{3}$ investigates whether a firm is more likely to export to a country from which it imports.
} 
$\lambda_{1}$ captures the effect of the export growth (between years $t$ and $t+1$ ) of Chilean firms which import from the Colombian firm $i$;

$\lambda_{2}$ captures the effect of the average import growth by country $c$ from all other countries between years $t$ and $t+1$;

$\delta$ accounts for the effect of economic size since firms are mechanically more likely to export to large countries with greater market size.

To examine which of the above mentioned factors contribute to persistent export expansion, we also estimate the effect of the same independent variables on the Survival dummy, which is defined as one if the exports to a new destination persist for more than a year and zero otherwise:

$$
\begin{aligned}
& \operatorname{Prob}\left(\text { Survival }_{i, c, t+1}>0 \mid \text { observables }\right) \\
& =\Phi\left(\alpha^{\prime} \text { Spillover }_{i, c, t}\right. \\
& +\beta_{1}^{\prime} \operatorname{ExpNetwork}_{i, c, t}+\beta_{2}^{\prime} C H L_{-} \operatorname{ImpNetwork}_{i, c, t}+\beta_{3}^{\prime} C O L_{-} \text {ImpNetwor } k_{i, c, t} \\
& +\gamma_{1}^{\prime} C O L \_ \text {proximity }+\gamma_{2}^{\prime} \text { CHL_proximity }{ }_{c}+\gamma_{3}^{\prime} \text { Overall_proximity } \\
& +\lambda_{1}^{\prime} C H L \_E x p G r o w t h_{i, c, t}+\lambda_{2}^{\prime} \text { Overall_ImpGrowt } h_{c, t} \\
& \left.+\delta^{\prime} G D P_{c, t}\right)
\end{aligned}
$$

Main Conjectures. Our main focus is on the Spillover and Networks coefficients: $\alpha$, $\beta_{1}, \beta_{2}$, and $\beta_{3}$. Specifically, we expect the spillover and export network effects to be significantly positive. If there exists other Colombian firms exporting the same product to a particular country, it implies the consumer preferences, competition intensity, and other market characteristics of that country are potentially desirable for the Colombian exporters of that product. ${ }^{16}$ Therefore, the Colombian firm would be more likely to export to that country as it has a higher chance to succeed there, i.e., $\alpha>0$. In addition, according to the remote search idea in Chaney (2014), a Colombian firm that has acquired a trade partner in Chile would search for new trade partners just like Chilean firms would. Thus, we would expect the Colombian firm to choose a new export destination just as its Chilean trade partners, i.e., $\beta_{1}>0$.

Note that export networks described above are likely to contain detailed information

\footnotetext{
${ }^{16}$ See, for example, Greenaway et al. (2004), Silvente and Giménez (2007), Koenig et al. (2010).
} 
about products exported by Colombian firms potentially embedded in the exports of Chilean firms which may have used the original Colombian product as an intermediate. This type of information is not present through either Colombian or Chilean import networks. Thus, we expect the import network effects to be either smaller or statistically insignificant.

All proximity variables have been also used in Chaney (2014)'s original specification. Chaney (2014) expected for coefficients $\gamma_{1}$ and $\gamma_{2}$ to be positive and statistically significant as firms are expected to be more likely to enter the markets closer to the exporting country and to the firm's previous export destinations. Coefficient $\gamma_{3}$, on the other hand, was expected to be negative, since we would expect the level of competition to be higher in countries which are closer to other countries, making it more difficult to break into this market.

At the same time both Colombian and Chilean proximity variables are positively correlated with both Spillover and Export Network dummies, which were not present in Chaney (2014)'s specification. Similarly, the Overall proximity is negatively correlated with these dummies. As a result, the presence of the Spillover and Export Network dummies is likely to decrease the magnitudes of the geographic proximity effects on the choice of the new export destination.

Finally, the effect of the export growth of Chilean firms which import from Colombian firm $i$ is expected to have a positive effect on the choice of new export destination. As motivated by Chaney (2014), the trade flows between the Chilean trade partners and country $c$ can be used as a proxy for the intensity of their communication. If there is an export growth from these Chilean trade partners to country $c$, it implies that the communication between them increases and the exposure of the exporting firm $i$ rises and as a result, we would expect the firm to be more likely to enter this new market. Note that we measure only the export growth of the direct Chilean importers from a Colombian firm to the third country, whereas Chaney (2014) measured the export growth of the entire country importing from a French firm to the third country. Thus, we expect our measure to be more directly linked to the network theory. Again, as with the geographic proximity effects, the presence of the Spillover and Export Network dummies is likely to dampen the export growth effects. 
Results. Table 3 summarizes the estimation results of equations (1) and (2). We present the estimated marginal effects rather than the coefficients to aid interpretation. Column (1)-(3) present the results for the expansion to new export destinations and column (4)-(6) present the results for the survival of these export expansions.

Table 3: Estimated Marginal Effects of Domestic Spillover and Foreign Network

\begin{tabular}{|c|c|c|c|c|c|c|}
\hline \multirow[b]{2}{*}{ Dependent Variable } & \multicolumn{3}{|c|}{ Probability of Entry } & \multicolumn{3}{|c|}{ Probability of Survival } \\
\hline & $(1)$ & $(2)$ & $(3)$ & (4) & $(5)$ & (6) \\
\hline \multirow[t]{2}{*}{ Spillover } & $0.0113^{* * *}$ & & $0.0108^{* * *}$ & $0.0054^{* *}$ & & $0.0053^{* *}$ \\
\hline & $(0.0036)$ & & $(0.0035)$ & $(0.0027)$ & & $(0.0027)$ \\
\hline \multirow[t]{2}{*}{ ExpNetwork } & & $0.0069^{* *}$ & $0.0042^{* *}$ & & 0.0002 & 0.0001 \\
\hline & & $(0.0031)$ & $(0.0017)$ & & $(0.0008)$ & $(0.0002)$ \\
\hline \multirow[t]{2}{*}{ CHL_ImpNetwork } & & 0.001 & 0.0004 & & 0.0008 & 0.0002 \\
\hline & & $(0.0014)$ & $(0.0007)$ & & $(0.0011)$ & $(0.0003)$ \\
\hline \multirow[t]{2}{*}{ COL_ImpNetwork } & & 0.0031 & 0.0012 & & -0.0002 & -0.0001 \\
\hline & & $(0.0025)$ & $(0.001)$ & & $(0.0005)$ & $(0.0001)$ \\
\hline \multirow[t]{2}{*}{ COL_proximity } & $0.0035^{* * *}$ & $0.0097^{* * *}$ & $0.0034^{* * *}$ & 0.0004 & $0.0031^{* *}$ & 0.0004 \\
\hline & $(0.0007)$ & $(0.002)$ & $(0.0007)$ & $(0.0002)$ & $(0.0012)$ & $(0.0002)$ \\
\hline \multirow[t]{2}{*}{ CHL_proximity } & $0.0029 * * *$ & $0.0067^{* * *}$ & $0.0023^{* *}$ & 0.0002 & $0.0025^{* *}$ & 0.0002 \\
\hline & $(0.001)$ & $(0.0017)$ & $(0.0009)$ & $(0.0003)$ & $(0.001)$ & $(0.0002)$ \\
\hline \multirow[t]{2}{*}{ overall_proximity } & $-0.0053^{* * *}$ & $-0.0093^{* * *}$ & $-0.0047^{* * *}$ & $-0.0007^{* *}$ & $-0.0035^{* * *}$ & $-0.0007^{* *}$ \\
\hline & $(0.001)$ & $(0.0017)$ & $(0.0011)$ & $(0.0003)$ & $(0.001)$ & $(0.0003)$ \\
\hline \multirow[t]{2}{*}{ CHL_ExpGrowth } & $0.00003^{* *}$ & $0.00004^{*}$ & $0.00002^{*}$ & $-9.26 \times 10^{-7}$ & $-6.22 \times 10^{-6}$ & $-1.67 \times 10^{-6}$ \\
\hline & $(0.00001)$ & $(0.00002)$ & $(0.00001)$ & $(0.0000)$ & $(0.00001)$ & $(0.0000)$ \\
\hline \multirow[t]{2}{*}{ overall_ImpGrowth } & $-6.83 \times 10^{-11}$ & $-1.25 \times 10^{-10}$ & $-7.59 \times 10^{-11}$ & $-1.68 \times 10^{-10}$ & $-4.56 \times 10^{-10}$ & $-1.63 \times 10^{-10}$ \\
\hline & $(0.0000)$ & $(0.0000)$ & $(0.0000)$ & $(0.0000)$ & $(0.0000)$ & $(0.0000)$ \\
\hline \multirow[t]{2}{*}{ GDP } & $2.89 \times 10^{-12 * * *}$ & $6.5 \times 10^{-12 * * *}$ & $2.49 \times 10^{-12 * * *}$ & $3.45 \times 10^{-13}$ & $2.37 \times 10^{-12 * *}$ & $3.2 \times 10^{-13}$ \\
\hline & $(0.0000)$ & $(0.0000)$ & $(0.0000)$ & $(0.0000)$ & $(0.0000)$ & $(0.0000)$ \\
\hline Years & $2007-2015$ & $2007-2015$ & $2007-2015$ & $2007-2014$ & 2007-2014 & $2007-2014$ \\
\hline No. of obs. & 29,666 & 29,666 & 29,666 & 23,660 & 23,660 & 23,660 \\
\hline R-square & 0.3192 & 0.2656 & 0.3294 & 0.2987 & 0.2051 & 0.3006 \\
\hline
\end{tabular}

Notes: This table shows the marginal effects for the Probit estimation of equation (1) and (2) for 163 Colombian expanding exporters between 2007 and 2016. Column (1)-(3) present the results for expansion to new export destinations and column (4)-(6) present results for the survival of these export expansions. The marginal effect is calculated as $d y / d x$ at the average value of each $x$ in the sample. $d y / d x$ stands for a discrete change from 0 to 1 when $x$ is a dummy variable. Standard errors are clustered at the firm level. *** Significant at the 1\% level. ** Significant at the 5\% level. * Significant at the $10 \%$ level.

The results suggest that only the Spillover and Export Network have statistically significantly positive effects on a firm's choice of new export destinations while neither of the Import Networks does. On average, a Colombian firm is $1.08 \%$ more likely to export to a new country if at least one other Colombian firm exported the same HS 10digit product to that country in the previous period (Spillover) and $0.42 \%$ more likely to choose a new export destination if its Chilean importer exported to that country in the previous period (Foreign Network). 
Our data allow us to provide more direct evidence on the importance of export networks for targeting new destinations than the previous literature. Chaney (2014) used French firm-to-country trade to examine the network effects. He defined a firm's network of trade partners as the existing portfolio of its export destinations, and showed that the existing export destinations shape a firm's future expansions into new markets.

Recent empirical and theoretical literature on matching and networks in trade, however, emphasizes the firm-to-consumer and firm-to-firm matching. That is, exporting firms connect with only a subset of all consumers and firms in a given location. ${ }^{17}$ In line with this literature, we exploring firm-to-firm networks which allows us to provide more direct evidence for network effects. Specifically, we show that a Colombian firm is more likely to choose a new export destinations if its Chilean importing counterpart was has been exporting to it before.

In line with our conjectures both Colombian and Chilean Import Network effects are statistically insignificant. Thus, being connected with other countries without information embedded in exported product (as in Export Networks) is unlikely to have an effect on choosing the next destination for expansion.

Column 3 of Table 3 indicates that, in the Entry regression, all proximity coefficients have the expected signs. Furthermore, the comparison of columns 1 and 2 to columns 3 shows that omitting Spillover dummy in the empirical specification produces a very pronounced upward bias in the magnitudes of the coefficients, while omitting the Network dummies has only a marginal effect on the magnitudes of the coefficients. According to column 6 of Table 3, in the presence of the Spillover dummy, none of the proximity variables affects the probability of survival for more than one year of exporting to a new destination.

Similarly, the export and import growth coefficients are of the expected sign in the Entry regression, and their magnitudes increase substantially in the specification with the omitted Spillover dummy. Neither import nor export growth effects are statistically significant in the Survival regression (column 6).

\footnotetext{
${ }^{17}$ In the context of international trade these ideas have been emphasized and formalized in the recent work of Arkolakis (2010) and Chaney (2014) among others. They also provide detailed reviews of the relevant network and matching literatures.
} 
Overall, by comparing the estimated results in column (1) and (2) to column (3), we found that estimating the Spillover and Foreign Network effects separately would result in an overestimation of all other effects in our model, which suggests a pronounced omitted variable bias. It is thus more appropriate and accurate to jointly estimate these effects together.

Economic Significance. Our results show that the spillover and export network effects are jointly more important than the proximity, export and import growth, and market size factors combined. To illustrate this point, we compute the fitted probability of choosing a particular country as the new export destination under four scenarios: (i) All other effects for a given country except for Export Network and Spillover effects; (ii) All other effects for a given country plus Export Network (but not Spillover) effect; (iii) All other effects for a given country plus Spillover (but not Export Network) effect; (iv) All other effects for a given country plus Spillover and Export Network effects.

The results are present in Figure 2. The graphs demonstrate several important findings. First, Colombian firms have much higher chances to expand to North American and Latin American countries compared to European, Asian, and other countries. Second, the probability of expanding to a new export destination increases significantly when either the spillover or the network effects are present. Third, the domestic spillover effect is stronger than the export network effect. Finally when both effects are present, the probability reaches its peak. For example, the probability of choosing the U.S. as the next export destination is only $2.7 \%$ if none of the effects is present, $7.8 \%$ with the export network effect only, $15.9 \%$ with the spillover effect only, and $31.2 \%$ if both export network and spillover effects are present.

Similarly, we compute the fitted probability of surviving more than one year for the exports to new destinations and present the results in Figure 3. The new exports to North American and Latin American countries are much more likely to persist for more than one year, as compared to European, Asian, and other countries. Importantly, Spillover effects is the only statistically significant one, and its economic effect is much more pronounced than any other effect, including the Foreign Export Network effect. Specifically, the export to a new destination is $0.53 \%$ more likely to persist for 

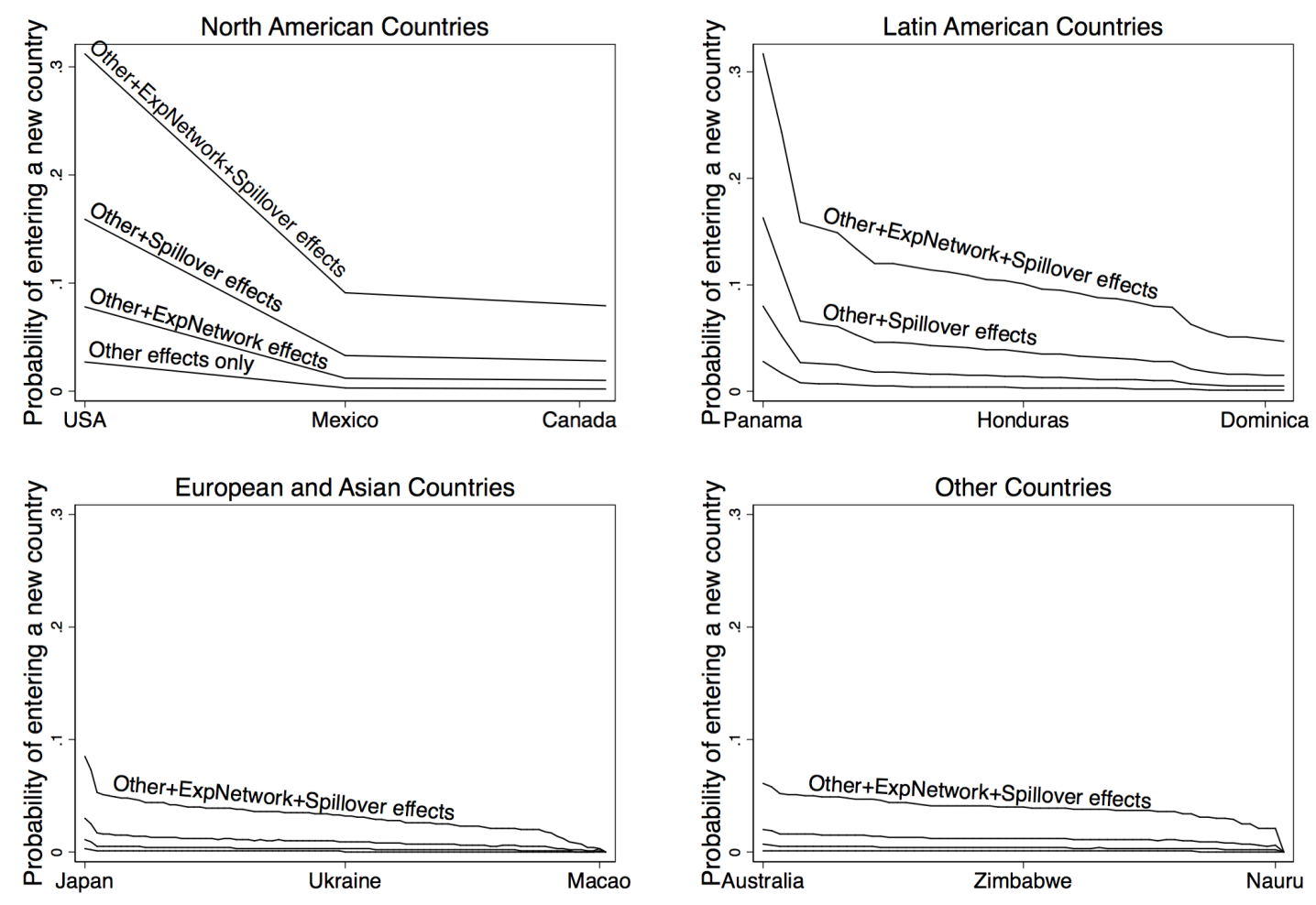

Figure 2: Probability of Choosing a New Export Destination (in 2007)

Note: The order of the lines in the above graphs are the same. Form the top to the bottom: with network, spillover, and other effects, with spillover and other effects, with network and other effects, and with other effects only.

more than a year if there was another Colombian firm exporting the same product to that destination in the previous year. This result demonstrates the difficulty in the persistent exporting to new destinations and re-emphasizes the importance of pioneers for successful self-discovery (Hausmann and Rodrik, 2003).

As in the Entry regression, the new exports are most likely to persist when both domestic spillover and export network effects are present. For example, for the new export to the U.S., the probability of surviving more than one year is only $0.3 \%$ if none of the effects is present, $0.4 \%$ with the export network effect only, $7.2 \%$ with the spillover effect only, and $8.6 \%$ if both export network and spillover effects are present.

Importantly, while not statistically significant, the signs of our other coefficients tend to be in line with the previous research. For example, Colombian firms tend to choose a new export destination that is closely connected to their previous export destinations, 

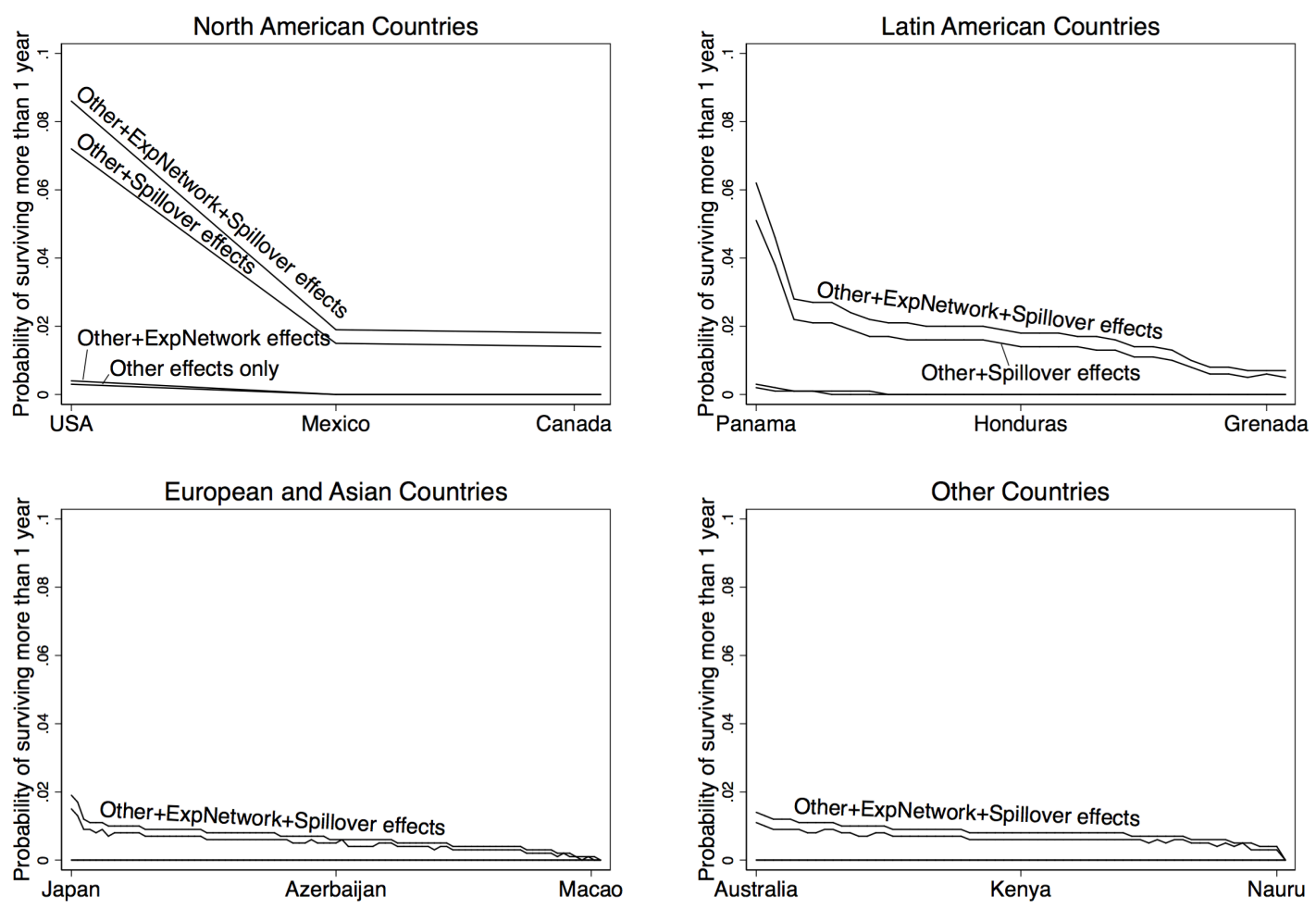

Figure 3: Probability of Surviving More Than One Year (in 2007)

Note: The order of the lines in the above graphs are the same. Form the top to the bottom: with network, spillover, and other effects, with spillover and other effects, with network and other effects, and with other effects only.

either in the sense that it is geographically close, or that it trades a lot with the previous trade partners. These findings are consistent with that of Lawless (2013), Morales et al. (2014), Chaney (2014), and Defever et al. (2015), confirming the important role played by previous export destinations on a firm's expansion path.

\section{Conclusion}

This paper explores the effects of domestic spillovers and foreign networks on an exporting firm's expansion into new foreign markets. By matching Colombian exporting and Chilean importing and exporting firms between 2007 and 2016, we show that both effects have statistically and economically significant positive effects on a firm's choice of new export destinations. Moreover, domestic spillover effects are relatively more 
important, especially for the survival or persistence of a new exporting relationship.

While there is a large literature focusing on the spillover and network effects on a firm's expansion to new foreign markets, our paper is the first to jointly estimate these two effects together. Thus, we provide a more complete and accurate estimation of these two effects without severe omitted variable bias. More importantly, the joint estimation allows us to identify the spillover effect, among all other effects, as the most important factor influencing a firm's choice of new export destinations. Additionally, we construct a new matched exporter-importer dataset to examine the network effects. The finer, firm-to-firm measures of networks is more accurate and informative than the previously used firm-to-country measures of networks.

Although this paper provides empirical evidence for the spillover and network effects in a firm's expansion to new foreign markets, it is still imperative to formulate a theoretical model that substantiates these effects. Moreover, this paper only analyzes the

network and spillover effects on the extensive margin of trade (i.e., the expansion to new markets) but remains silent on their effects on the intensive margins (i.e. how much the firm sells to each market). A model for network and spillover effects on the intensive margin of trade would thus also be interesting. Finally, with the increasing availability of firm-level trade data, it is possible to check whether the results of this paper can be generalized to the trade between other countries. These questions are left for future research.

\section{References}

Aitken, B., Hanson, G. H., and Harrison, A. E. (1997). Spillovers, foreign investment, and export behavior. Journal of International economics, 43(1-2):103-132.

Albornoz, F., Pardo, H. F. C., Corcos, G., and Ornelas, E. (2012). Sequential exporting. Journal of International Economics, 88(1):17-31.

Aleksynska, M. and Peri, G. (2014). Isolating the network effect of immigrants on trade. The World Economy, 37(3):434-455. 
Antras, P. and Costinot, A. (2011). Intermediated trade. The Quarterly Journal of Economics, 126(3):1319-1374.

Arkolakis, C. (2010). Market penetration costs and the new consumers margin in international trade. Journal of political economy, 118(6):1151-1199.

Benguria, F. (2015). The matching and sorting of exporting and importing firms: theory and evidence.

Bernard, A. B. and Moxnes, A. (2018). Networks and trade. Annual Review of Economics, 10(1).

Bernard, A. B., Moxnes, A., and Ulltveit-Moe, K. H. (2014). Two-sided heterogeneity and trade. Review of Economics and Statistics, (0).

Blum, B. S., Claro, S., and Horstmann, I. (2010). Facts and figures on intermediated trade. American Economic Review, 100(2):419-23.

Blum, B. S., Claro, S., and Horstmann, I. J. (2012). Import intermediaries and trade costs: Theory and evidence. Unpublished manuscript, Rotman School of Management, University of Toronto.

Chaney, T. (2014). The network structure of international trade. The American Economic Review, 104(11):3600-3634.

Clerides, S. K., Lach, S., and Tybout, J. R. (1998). Is learning by exporting important? micro-dynamic evidence from colombia, mexico, and morocco. The quarterly journal of economics, 113(3):903-947.

Combes, P.-P., Lafourcade, M., and Mayer, T. (2005). The trade-creating effects of business and social networks: evidence from france. Journal of international Economics, 66(1):1-29.

Currarini, S., Jackson, M. O., and Pin, P. (2009). An economic model of friendship: Homophily, minorities, and segregation. Econometrica, 77(4):1003-1045.

Defever, F., Heid, B., and Larch, M. (2015). Spatial exporters. Journal of International Economics, 95(1):145-156. 
Dragusanu, R. (2014). Firm-to-firm matching along the global supply chain. Harvard University mimeo.

Eaton, J., Eslava, M., Krizan, C. J., Kugler, M., and Tybout, J. (2009). A search and learning model of export dynamics. Penn State University mimeo.

Eaton, J., Eslava, M., Kugler, M., and Tybout, J. (2007). Export dynamics in colombia: Firm-level evidence. Technical report, National Bureau of Economic Research.

Garmendia, A., Llano, C., Minondo, A., and Requena, F. (2012). Networks and the disappearance of the intranational home bias. Economics Letters, 116(2):178-182.

Greaney, T. M. (2009). Measuring network effects on trade: A reexamination. Japan and the World Economy, 21(3):219-225.

Greenaway, D., Sousa, N., and Wakelin, K. (2004). Do domestic firms learn to export from multinationals? European Journal of Political Economy, 20(4):1027-1043.

Hausmann, R. and Rodrik, D. (2003). Economic development as self-discovery. Journal of Development Economics, 72(2):603-633.

Iacovone, L. and Javorcik, B. S. (2010). Multi-product exporters: Product churning, uncertainty and export discoveries. The Economic Journal, 120(544):481-499.

Jackson, M. O. and Zenou, Y. (2015). Games on networks. In Handbook of game theory with economic applications, volume 4, pages 95-163. Elsevier.

Kneller, R. and Pisu, M. (2007). Industrial linkages and export spillovers from fdi. The World Economy, 30(1):105-134.

Koenig, P. (2009). Agglomeration and the export decisions of french firms. Journal of Urban Economics, 66(3):186-195.

Koenig, P., Mayneris, F., and Poncet, S. (2010). Local export spillovers in france. European Economic Review, 54(4):622-641.

Lawless, M. (2013). Marginal distance: Does export experience reduce firm trade costs? Open Economies Review, 24(5):819-841.

Monarch, R. (2014). It's not you, it's me: Breakups in us-china trade relationships. federal reserve board. Technical report, mimeo. 
Morales, E., Sheu, G., and Zahler, A. (2014). Gravity and extended gravity: Using moment inequalities to estimate a model of export entry. Technical report, National Bureau of Economic Research.

Nguyen, D. X. (2012). Demand uncertainty: Exporting delays and exporting failures. Journal of International Economics, 86(2):336-344.

Petropoulou, D. (2008). Information costs, networks and intermediation in international trade. Centre for Economic Performance, London School of Economics and Political Science.

Rauch, J. E. (1999). Networks versus markets in international trade. Journal of international Economics, 48(1):7-35.

Rauch, J. E. (2001). Business and social networks in international trade. Journal of economic literature, pages 1177-1203.

Rauch, J. E. and Trindade, V. (2002). Ethnic chinese networks in international trade. Review of Economics and Statistics, 84(1):116-130.

Rauch, J. E. and Watson, J. (2004). Network intermediaries in international trade. Journal of Economics \& Management Strategy, 13(1):69-93.

Silvente, F. R. and Giménez, J. C. (2007). Information spillovers and the choice of export destination: A multinomial logit analysis of spanish young smes. Small Business Economics, 28(1):69-86.

Wagner, R. and Zahler, A. (2015). New exports from emerging markets: do followers benefit from pioneers? Journal of Development Economics, 114:203-223. 


\section{Appendix}

\section{A Technical notes on firm-to-firm matching}

Matching Colombian exporting firms to their Chilean trade partners plays a critical role in estimating foreign network effects in our paper. We manage to do this as the Colombian firm-level export data record the name and address of the foreign importing firm for each transaction. However, the foreign firm name data are very noisy. There are instances in which the same firm is recorded differently by using various abbreviations, extra spaces, dashes, dots, and other special signs. To clean and match the importing firm names, we used the following procedure:

1. We dropped all observations with the missing importing firm names.

2. We eliminated the typical prefixes, suffixes, and abbreviations (e.g., "LTDA", "LLC", "CO.", "INC").

3. We eliminated the non alpha numeric characters (e.g., . / ; () @ \&).

4. We compared the importing firm names with the standardized firm names recorded in the Chilean imports data. If the firm names are the same, we accomplish a match.

5. There are cases that the firm names have slightly different spelling than the standardized firm names. In these cases, we perform a further match by address. Specifically, we searched the address of the standardized firm through Internet, and compared it with the address recorded in Colombian export data. If the addresses are the same, we match the two firms. Otherwise we fail to match. 


\section{B Robustness Check: Logit model}

Table A: Estimated Marginal Effects of Domestic Spillover and Foreign Network

\begin{tabular}{|c|c|c|c|c|c|c|}
\hline \multirow[b]{2}{*}{ Dependent Variable } & \multicolumn{3}{|c|}{ Probability of Entry } & \multicolumn{3}{|c|}{ Probability of Survival } \\
\hline & $(1)$ & $(2)$ & $(3)$ & $(4)$ & $(5)$ & (6) \\
\hline Spillover & $\begin{array}{c}0.0106^{* * *} \\
(0.0018)\end{array}$ & & $\begin{array}{c}0.0104^{* * *} \\
(0.0017)\end{array}$ & $\begin{array}{c}0.0052^{* * *} \\
(0.0016)\end{array}$ & & $\begin{array}{c}0.0052^{* * *} \\
(0.0016)\end{array}$ \\
\hline ExpNetwork & & $\begin{array}{c}0.0041^{* *} \\
(0.0016)\end{array}$ & $\begin{array}{c}0.0025^{* *} \\
(0.001)\end{array}$ & & $\begin{array}{c}0.0001 \\
(0.0005)\end{array}$ & $\begin{array}{l}0.00003 \\
(0.0001)\end{array}$ \\
\hline CHL_ImpNetwork & & $\begin{array}{c}0.0004 \\
(0.0007)\end{array}$ & $\begin{array}{c}0.0002 \\
(0.0003)\end{array}$ & & $\begin{array}{c}0.0005 \\
(0.0006)\end{array}$ & $\begin{array}{c}0.0001 \\
(0.0001)\end{array}$ \\
\hline COL_ImpNetwork & & $\begin{array}{c}0.0016 \\
(0.0011)\end{array}$ & $\begin{array}{c}0.0006 \\
(0.0005)\end{array}$ & & $\begin{array}{l}-0.0002 \\
(0.0004)\end{array}$ & $\begin{array}{c}-0.00004 \\
(0.0001)\end{array}$ \\
\hline COL_proximity & $\begin{array}{c}0.0027^{* * *} \\
(0.0005)\end{array}$ & $\begin{array}{c}0.0077^{* * *} \\
(0.001)\end{array}$ & $\begin{array}{c}0.0027^{* * *} \\
(0.0005)\end{array}$ & $\begin{array}{c}0.0002 \\
(0.0002)\end{array}$ & $\begin{array}{c}0.0025^{* * *} \\
(0.0006)\end{array}$ & $\begin{array}{c}0.0002 \\
(0.0002)\end{array}$ \\
\hline CHL_proximity & $\begin{array}{c}0.0021^{* * *} \\
(0.0007)\end{array}$ & $\begin{array}{c}0.0059^{* * *} \\
(0.0013)\end{array}$ & $\begin{array}{c}0.0018^{* *} \\
(0.0007)\end{array}$ & $\begin{array}{c}0.0001 \\
(0.0002)\end{array}$ & $\begin{array}{l}0.002^{* *} \\
(0.0009)\end{array}$ & $\begin{array}{c}0.0001 \\
(0.0002)\end{array}$ \\
\hline overall_proximity & $\begin{array}{c}-0.0053^{* * * *} \\
(0.0012)\end{array}$ & $\begin{array}{c}-0.0102^{* * * *} \\
(0.0019)\end{array}$ & $\begin{array}{c}-0.0047^{* * *} \\
(0.0012)\end{array}$ & $\begin{array}{c}-0.0006 \\
(0.0004)\end{array}$ & $\begin{array}{c}-0.0038^{* * *} \\
(0.0012)\end{array}$ & $\begin{array}{l}-0.0006 \\
(0.0004)\end{array}$ \\
\hline CHL_ExpGrowth & $\begin{array}{c}0.00003^{* * *} \\
(0.0000)\end{array}$ & $\begin{array}{c}0.00003^{* * *} \\
(0.00001)\end{array}$ & $\begin{array}{c}0.00002^{* * *} \\
(0.0000)\end{array}$ & $\begin{array}{c}-5.51 \times 10^{-7} \\
(0.0000)\end{array}$ & $\begin{array}{c}-3.63 \times 10^{-6} \\
(0.0000)\end{array}$ & $\begin{array}{c}-8.38 \times 10^{-7} \\
(0.0000)\end{array}$ \\
\hline overall_ImpGrowth & $\begin{array}{c}-5.87 \times 10^{-11} \\
(0.0000)\end{array}$ & $\begin{array}{c}-9.81 \times 10^{-11} \\
(0.0000)\end{array}$ & $\begin{array}{c}-6.11 \times 10^{-11} \\
(0.0000)\end{array}$ & $\begin{array}{c}-8.18 \times 10^{-11} \\
(0.0000)\end{array}$ & $\begin{array}{c}-2.59 \times 10^{-10} \\
(0.0000)\end{array}$ & $\begin{array}{c}-8 \times 10^{-11} \\
(0.0000)\end{array}$ \\
\hline GDP & $\begin{array}{c}1.9 \times 10^{-12 * * *} \\
(0.0000)\end{array}$ & $\begin{array}{c}4.74 \times 10^{-12 * * *} \\
(0.0000)\end{array}$ & $\begin{array}{c}1.73 \times 10^{-12 * * *} \\
(0.0000)\end{array}$ & $\begin{array}{c}1.91 \times 10^{-13} \\
(0.0000)\end{array}$ & $\begin{array}{c}1.75 \times 10^{-12 * * *} \\
(0.0000)\end{array}$ & $\begin{array}{c}1.83 \times 10^{-13} \\
(0.0000)\end{array}$ \\
\hline Years & $2007-2015$ & $2007-2015$ & $2007-2015$ & $2007-2014$ & $2007-2014$ & $2007-2014$ \\
\hline No. of obs. & 29,666 & 29,666 & 29,666 & 23,660 & 23,660 & 23,660 \\
\hline R-square & 0.3145 & 0.2592 & 0.324 & 0.3005 & 0.2019 & 0.3016 \\
\hline
\end{tabular}

Notes: This table shows the marginal effects for the Logit estimation of equation (1) and (2) for 163 Colombian expanding exporters between 2007 and 2016. Column (1)-(3) present the results for expansion to new export destinations and column (4)-(6) present results for the survival of these export expansions. The marginal effect is calculated as $d y / d x$ at the average value of each $x$ in the sample. $d y / d x$ stands for a discrete change from 0 to 1 when $x$ is a dummy variable. Standard errors are clustered at the firm level. $* * *$ Significant at the $1 \%$ level. ** Significant at the $5 \%$ level. $*$ Significant at the $10 \%$ level. 